(C) N. A. Provorov, N. I. Vorobyov

All-Russia Research Institute for Agricultural Microbiology, St. Petersburg, Russia

\begin{abstract}
The mathematical model for evolution of legume-rhizobia mutualism based on the partners' positive feedbacks resulted from their metabolic $(\mathrm{C}-\mathrm{N})$ exchange is presented. Negative FDS in rhizobia population, combined with the partners' positive feedbacks ensure anchoring or even domination of the mutants which either acquired the mutualistic traits or changed the specificity in their expression with different host genotypes. The created model allows us to consider the mutualistic symbiosis as of a finely balanced population system in which the equilibrium may be shifted in favor of beneficial microbial genotypes due to natural selection for an improved symbiotic efficiency implemented in plant population.
\end{abstract}

Key words: mutualistic symbioses, plant-microbe interaction, positive feedbacks, frequency-dependent selection (FDS), Darwinian selection, root nodule bacteria, $\mathrm{N}_{2}$ fixation, mathematical simulation, symbiotic cheaters, evolution of symbioses.

\section{SIMULATION OF PLANT-BACTERIA CO-EVOLUTION IN THE MUTUALLY BENEFICIAL SYMBIOSIS}

\section{INTRODUCTION}

Beneficial (mutualistic) symbioses represent a highly efficient strategy for adaptation of organisms to the changing and stressful environments (Douglas, 1994). Due to symbioses with fungi or bacteria, plants can improve their nutrition, defense from pathogens and herbivores, resistance to abiotic stresses and growth regulation (Tikhonovich and Provorov, 2007). However, mechanisms for origin and maintenance of symbiotic mutualism remain obscure since in populations of interacting organisms, the "altruistic" genes are supported the primary functions of which are to benefit the symbiotic partners, not the owners of these genes (Person et al., 1962; Williams, 1966; Frank, 1994). For example, $\mathrm{N}_{2}$ fixed from atmosphere by root nodule bacteria (rhizobia) or phosphates assimilated from soil by arbuscular mycorrhizal (glomalean) fungi are donated from micro-symbionts to hosts and specialization for implementing these functions may be very deep, leading to a restriction of reproductive ability as it is typical for glomalean fungi (Smith and Read, 1997) and for rhizobial bacteroids (Brewin, 2004). Maintenance of the "altruistic" traits in microbial partners is easily explained for obligatory symbiotic interactions especially when the microbes are vertically transmitted in host generations (Darlington, 1978; Douglas, 1998; Denison and Kiers, 2004; Gundel et al., 2007). In the absence of vertical transmission, evolution of mutualism may be suppressed by a lineage mixing in micro-symbiont populations which favors the cheating (non-beneficial or even pathogenic) genotypes that mimic "genuine mutualists" without fulfilling their mutualistic obligations (Frank, 1996; Simms and Taylor, 2002).

A failure to reveal the selective mechanisms supporting the mutualistic interactions is largely due to ignorance of the evolutionary potential of functional feedbacks which integrate the partners due to operation at two levels: metabolic (bilateral exchange by nutrients) and population (co-evolutionary adaptations towards the environmental stresses). In antagonistic symbioses (pathogenic systems), the negative feedbacks dominate (Pimentel, 1968): increase of fitness in either partner is usually correlated to the decreased fitness in the other partner (e. g., high virulence is beneficial for pathogens but deleterious for hosts and vice versa). However, in mutualistic interactions, partners' feedbacks may be essentially positive since a symbiosis-specific increase of fitness in either partner improves fitness in the other one. Such feedbacks may result from operation of microbial genes which benefit the host directly, but for owners of this genes, improvement of fitness is mediated by a "return of costs" implemented by host more effectively the more benefit is obtained by host ("reciprocal altruism"; Frank, 1994).

Symbioses between rhizobia (a collective name for gram-negative bacteria, e. g., Rhizobium, Sinorhizobium, Bradyrhizobium, Mesorhizobium forming $\mathrm{N}_{2}$-fixing root nodules) and the leguminous plants (Fabaceae) represent very convenient models for analyzing the mechanisms of mutualism evolution because these symbioses are studied comprehensively at the molecular and population levels (Sessitsch et al., 2002). Herein, partners' feedbacks may be quantified on the basis of exchange with $\mathrm{C}$ - and $\mathrm{N}$-metabolites (Vance and Heichel, 1991 ): fixation of $\mathrm{N}_{2}$ by rhizobia stimulates photosynthesis (Bethlenfalvay et al., 1978) the products of which are used in nodules not only for the energy supply of nitrogenase and for assimilation of ammonium, but also for multiplication of the intra-nodule rhizobia population (Streeter, 1995; Tim- 
mers et al., 2000). These feedbacks can ensure the regular reorganizations in endo-symbiotic microbial populations eliciting the selective pressures responsible for evolution of host-beneficial (mutualistic) traits. For example, allocation of host-derived $\mathrm{C}$ compounds in favor of $\mathrm{N}_{2}$-fixing strains in combination with the hosts' "sanctions" against non- $\mathrm{N}_{2}$-fixing strains (Denison and Kiers, 2004) can ensure the preferential in planta multiplication of $\mathrm{N}_{2}$-fixing strains resulted in the group (inter-deme) selection in favor of symbiotic mutualism (Provorov et al., 2008). However, efficiency of this selection may be restricted greatly by the mixed nodule infections due to which many nodules formed under field conditions contain compositions of $\mathrm{N}_{2}$ fixing and non-fixing strains. The later may be the most active consumers of $\mathrm{C}$ compounds behaving as "symbiotic cheaters" which are often found in mutualistic symbioses in a stable equilibrium with "genuine mutualists" (Darlington, 1978; Douglas, 1998; Simms and Taylor, 2002; Denison and Kiers, 2004).

In order to simulate evolution in rhizobia-legume mutualism, we modified the previously developed models of cyclic processes in microbe-plant systems (Provorov and Vorobyov, 2000, 2006) which represent formation of highly polymorphic and panmicitic rhizobia populations as a result of negative frequency dependent selection (FDS) operating during competition for nodulation. The positive partners' feedbacks are described assuming that: (i) plants and bacteria are represented by dimorphic populations the components of which combine randomly into symbiotic systems differing in ability to fix $\mathrm{N}_{2}$; (ii) fitness (reproductive success) in both partners is determined by the efficiency of $\mathrm{N}_{2}$-fixation. This approach enables us to study the interplay of FDS and Darwinian selection in co-evolving partners' populations which results in anchoring and even domination of "genuine mutualists" ( $\mathrm{N}_{2}$-fixing strains) over the "symbiotic cheaters" (non-fixing strains) maintained at an equilibrium in "plant-soil" system.

\section{CONSTRUCTION OF THE MODEL FOR MUTUALISTIC SYMBIOSIS}

Let us consider that in the simulated system, microsymbionts occupy three habitats (soil, rhizosphere, nodules), while the hosts occupy one habitat (wherein they exist as symbiotically active plants or as dormant seeds). The coordinated partners' microevolution is represented by a cyclic process; genetic structure of symbiotic system (frequencies of partners' genotypes) formed at the end of $t$-th cycle constitute the starting conditions for the $(t+1)$-th cycle (in the relevant recurrent equations, variables depending on the number of cycle are given in italics).

At each cycle, partners implement the successive interactions: rhizobia inoculate symbiotic (rhizospheral and nodular) habitats in juvenile plants and colonize these habitats (multiply within nodules and rhizospheres) in mature plants. After seed formation, plants extinct and bacteria from rhizosphere and nodules are released into soil (Fig. 1).

Model involves the partners' feedbacks assuming that: 1 ) frequency of $\mathrm{N}_{2}$-fixing strain in nodules determines the reproductive success in hosts ("bacteria $\rightarrow$ plant" positive feedback) and in endosymbiotic bacteria (auto-induction of bacteria propagation); 2) ratio of two genotypes in plant population determines the volumes of symbiotic (rhizospheral and nodular) sub-habitats provided by plant genotypes for bacteria occupation ("plant $\rightarrow$ bacteria" feedback).

\section{Step 1. Mutational process in the soil bacterial population}

In the simulated system, rhizobia are represented by mutant $(M)$ and its parent $(P)$ contrasting in the abilities to form $\mathrm{N}_{2}$-fixing symbioses with two available plant genotypes; plants — by a pair of genotypes each forms $\mathrm{N}_{2}$-fixing symbioses with one of two rhizobia strains. We consider two types of $\mathrm{P} \rightarrow \mathrm{M}$ mutations (reverse mutations are not considered):

1-st type: $M$ fixes $\mathrm{N}_{2}$ in symbiosis with both plant genotypes ("genuine mutualists") while P is devoid of this ability ("symbiotic cheaters"); these mutations type represents acquisition of the host-beneficial (mutualistic) traits by bacteria;

2-nd type: $M$ fixes $N_{2}$ in symbiosis with 1 -st, not with 2-nd plant genotype, while $P$ fixes $\mathrm{N}_{2}$ with 2 -nd plant genotype only; these mutations represents the changes in host-specific expression of beneficial traits in bacteria.

At the beginning of Step 1, numbers of $M$ and $P$ cells are $Q_{1 \text { MS.t }}$ and $Q_{I P S . t}$, while to the end of Step 1 they are changed for $Q_{2 M S . t}$ and $Q_{2 P S . t}$ according to formulae from Table 1 (rearrangement 1.1 ).

\section{Step 2. Competitive processes related to seed germination and to inoculation of symbiotic habitats}

Competition in plant population during seed germination. At the beginning of Step 2, plant population is represented by seeds the numbers of which for 1 -st and 2 -nd genotypes are $Q p_{11 . t}$ and $Q p_{12 . t}$. During this Step, seeds germinate and juvenile plants compete for survival resulting in decrease of total population size to the constant level $\left(\mathrm{P}_{0}=Q p_{21 . t}+Q p_{22 . t}\right)$ according to formulae from Table 2 (rearrangement 2.1). The structure of resulted population is characterized by variable $\alpha_{t}=Q p_{21 . t}: \mathrm{P}_{0}$ $\left(0<\alpha_{t}<1\right)$ used later to determine the ratios of total numbers of bacteria hosted by 1 -st and 2 -nd plant genotypes within symbiotic habitats after their inoculation.

Competition for inoculation of symbiotic habitats by bacteria. Juvenile plants offer the symbiotic habitats for inoculation which is represented as a migration of bacteria from soil into rhizosphere and nodules at the end of which the size and structure of soil population is restored due to 


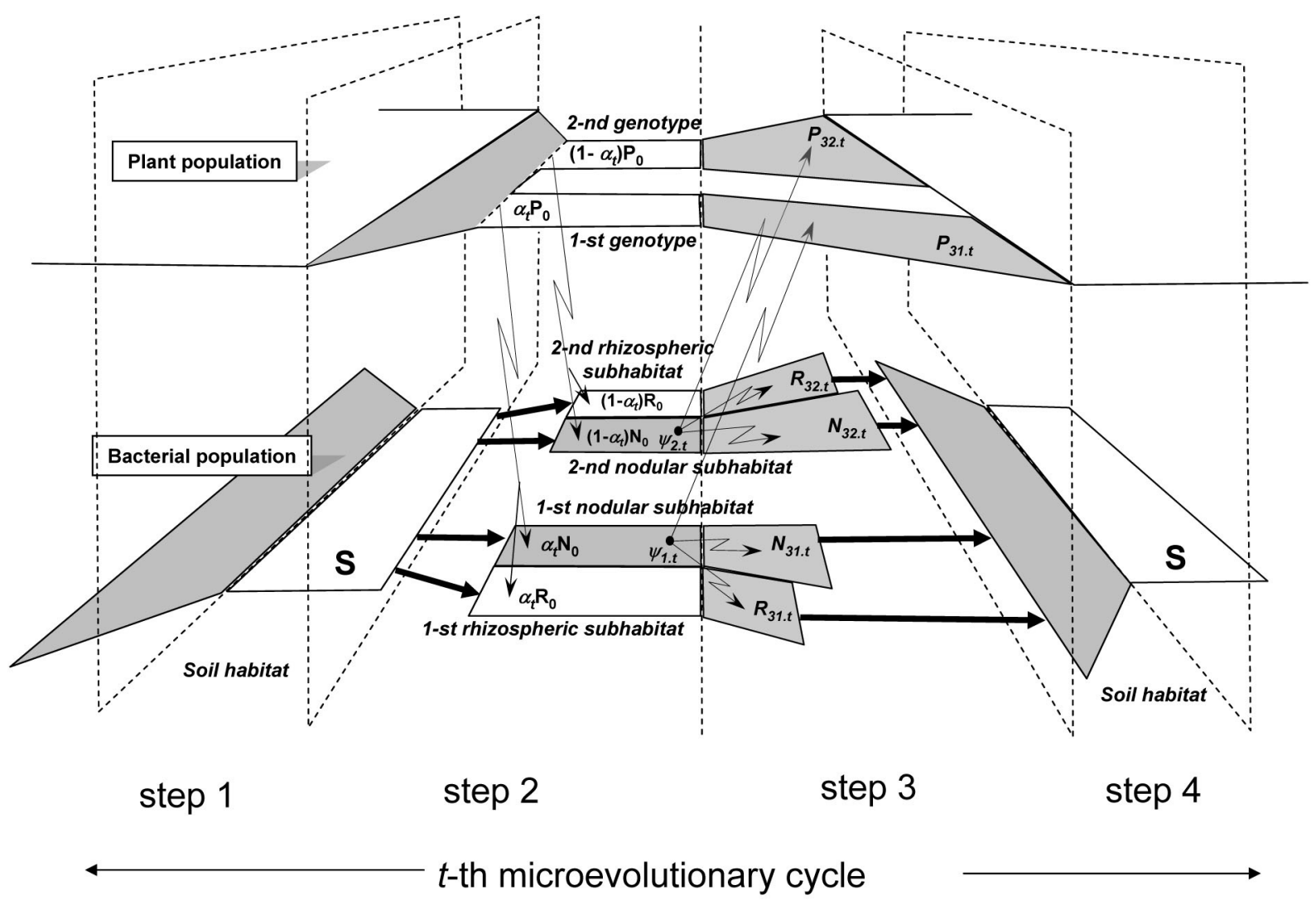

Fig. 1. Schematic representation of $t$-th microevolutionary cycle of the rhizobia-legume system evolving under the impacts of partners' feedbacks.

Broken thin arrows represent the partners' feedbacks determined by parameters: $\alpha_{t}$ (proportion of 1 -st genotype in plant population); $\psi_{\text {I.t }}$ and $\psi_{2 . t}$ (frequencies of $\mathrm{N}_{2}$-fixing strains in the nodular sub-habitats of 1 -st and 2 -nd plant genotypes after their inoculation). Solid arrows show migration of bacteria among habitats (from soil to rhizosphere during transition from Step 1 to Step 2; from rhizosphere and nodules into soil during transition from Step 3 to Step 4).

Microevolutionary factors operating through the $t$-th cycle are describes in Section 2, while their mathematical descriptions are given in Tables 1 and 2 .

compensatory cell divisions. The total bacteria numbers $(M+P)$ in symbiotic habitats of all plants are constants: $\mathrm{R}_{0}, \mathrm{~N}_{0}$ are "Inoculation Volumes" (IV) offered by the plant population for bacteria introduced into rhizospheres and nodules, respectively. These habitats are dissected into sub-habitats formed by 1 -st and 2 -nd plant genotypes and having IV sizes dependent on $\alpha_{t}: R_{11 . t}=\alpha_{t} \times R_{0}$, $R_{12 . t}=(1-) \alpha_{t} \times R_{0}$ (rhizospheral sub-habitats); $N_{11 . t}=\alpha_{t} \times N_{0}$, $N_{12 . t}=(1-) \alpha_{t} \times N_{0}$ (nodular sub-habitats).

After inoculation of rhizospheral sub-habitats, ratios of bacterial genotypes in them are the same as in soil. At the end of Step 2, rhizospheral sub-habitats maintain the bacteria numbers calculated according to formulae from Table 1 (rearrangements 1.2, 1.3).

As we demonstrated previously (Provorov and Vorobyov, 2000, 2006), during inoculation of nodular subhabitats, in rhizobia population the negative Frequency Dependent Selection (FDS) occurs which is based on the empirically determined non-linear dependency between bacterial ratios in nodules and in inocula (Amarger and
Lobreau, 1982). Inoculation of nodular sub-habitats is a stochastic process represented by Bernoulli scheme. If number of $M$ at 1 -st microevolutionary cycle is not sufficient to inoculate a nodular sub-habitat, integral probability of this event is calculated for a sum of $1 . . . j$ cycles. This probability allows us to determine the $\mathrm{j}$-th cycle at which the nodule occupation by $M$ starts (at an integral probability $\geq 0.95$ ). At the end of Step 2 , numbers of bacteria in nodular sub-habitats of 1 -st and 2 -nd plant genotypes are calculated according to formulae from Table 1 (rearrangements 1.4, 1.5).

The resulted frequencies of $\mathrm{N}_{2}$-fixing rhizobia strains in the nodular sub-habitats of 1 -st and 2 -nd plant genotypes $\left(0 \leq \psi_{1, t}, \psi_{2, t} \leq 1\right.$; Table 1 , rearrangements $\left.1.4,1.5\right)$ are used later as the measures of symbiotic efficiency. This approach is based on the data demonstrating that in nodules containing a mixture of strains contrasting in ability for $\mathrm{N}_{2}$-fixation, the nitrogenase activity may be intermediate with respect to nodules containing either of these strains solely (Bassam et al., 1987). 


\section{Step 3. Microevolutionary processes related to colonization of symbiotic habitats and to seed formation}

Colonization of symbiotic habitats by bacteria. Let us assume that the reproductive potential of partners which represents a universal measure of their fitness (TimofeeffRessovsky et al., 1977) depends on the symbiotic efficiency. This assumption is based on the data demonstrating that the more proportion of nodules contain $\mathrm{Fix}^{+}$strain, the more nutrients are obtained by plants (fixed $\mathrm{N}$ used for seed formation) and by bacteria (C compounds allocated to the nodules and used for the cell propagation) (Streeter, 1995; Timmers et al., 2000; Kiers et al., 2003).

The influence of symbiotic efficiency on bacterial fitness is presented as the dependencies of "Colonization Volumes" (CV) offered by plants for bacteria in symbiotic sub-habitats on the initial frequencies of $\mathrm{N}_{2}$-fixing strains in nodules, $\psi_{1 . t}$ and $\psi_{2 . t}$ (these dependencies are approximated by functions from Table 1, rearrangements 1.6-1.9).

In order to describe the relevant microevolutionary processes we suggest that colonization of symbiotic subhabitats occurs due to multiplication of bacteria which reside in these sub-habitats after inoculation. During colonization of symbiotic sub-habitats, competition between bacteria genotypes occurs due to their differential multiplication. The ratios of $\mathrm{P}: M$ multiplication rates in rhizospheral (v1, v2) and nodular $(\omega 1, \omega 2)$ sub-habitats determine the relevant Darwinian selection pressures. Their operation is described by logistic equations adapted for the pairs of genotypes in populations with fixed finite sizes (Kubitschek, 1974) which are dependent on coefficients $\psi_{1 . t}$ and $\psi_{2 . t}$ (Table 1, rearrangements 1.6-1.9).

Alterations in numbers of mutant (M) and parental (P) bacteria at the successive Steps of $t$-th microevolutionary cycle

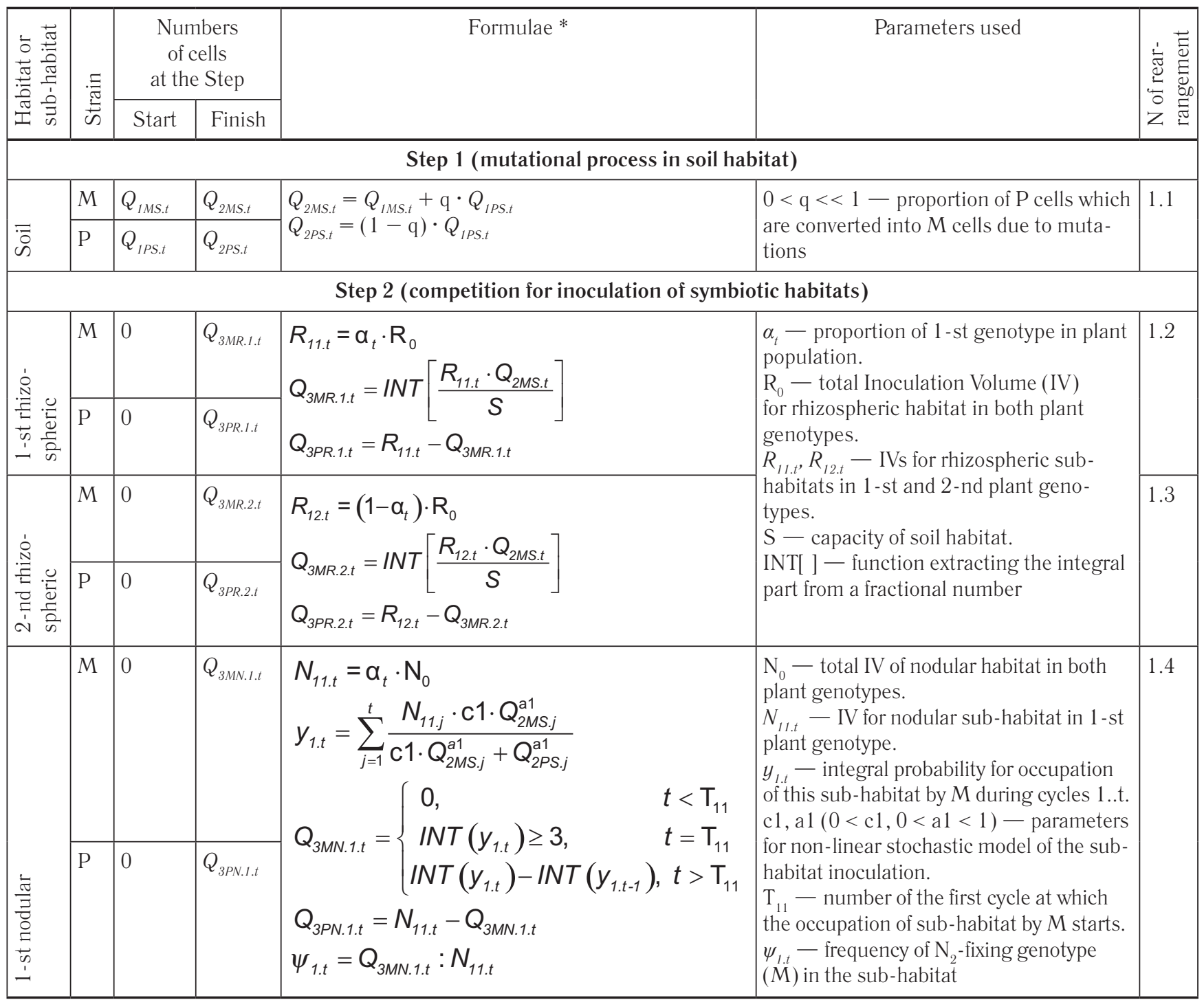


Table 1 (continue)

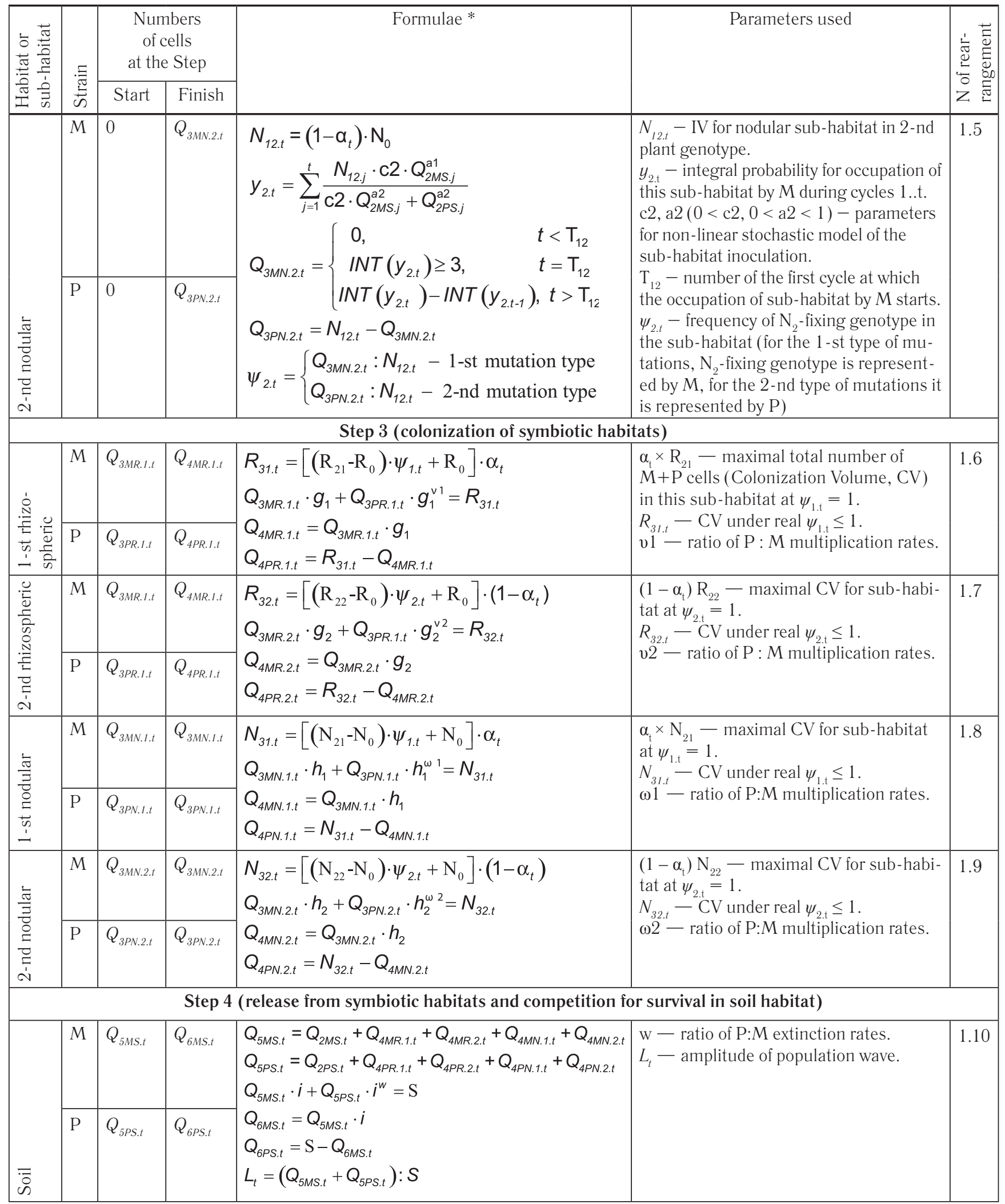

* Variables (parameters dependent on the number of cycle, $\mathrm{t}$ ) are given in italics.

In order to implement recurrent calculations, $M$ and $\mathrm{P}$ bacteria numbers obtained at the end of Step 4 of $\mathrm{t}$-th cycle used as starting conditions Step 1 of $(\mathrm{t}+1)$-th cycle: $Q_{1 M S . t+1}=Q_{6 M S . t}, Q_{I P S . t+1}=Q_{6 P S . t}$. 
Table 2

Alterations in the numbers of different genotypes in plant population at Steps 2 and 3 of $t$-th microevolutionary cycle

\begin{tabular}{|c|c|c|c|c|c|c|}
\hline \multirow[t]{2}{*}{ Step } & \multirow{2}{*}{ 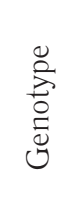 } & \multicolumn{2}{|c|}{$\begin{array}{l}\text { Numbers of } \\
\text { plants at the } \\
\text { Step* }\end{array}$} & \multirow[t]{2}{*}{ Formulae** } & \multirow[t]{2}{*}{ Parameters used } & \multirow{2}{*}{ 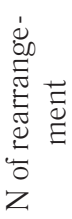 } \\
\hline & & Start & Finish & & & \\
\hline \multirow{2}{*}{2} & 1 -st & $Q p_{11 . t}{ }^{*}$ & $Q p_{21 . t}$ & \multirow{2}{*}{$\begin{array}{l}Q p_{21 . t}=\frac{P_{0} \cdot c p \cdot Q p_{11 . t}^{\lambda}}{c p \cdot Q p_{11 . t}^{\lambda}+Q p_{12 . t}^{\lambda}} \\
Q p_{22 . t}=P_{0}-Q p_{21 . t} \\
\alpha_{t}=Q p_{21 . t}: P_{0}\end{array}$} & \multirow{2}{*}{$\begin{array}{l}\mathrm{P}_{0}-\text { total number of plants at the end } \\
\text { of Step } 2 . \\
\mathrm{cp}, \lambda(\mathrm{cp}>0, \lambda>0)-\text { coefficients for } \\
\text { model of competition which occurs } \\
\text { during the seedling development. } \\
\alpha_{\mathrm{t}}-\text { proportion of } 1 \text {-st genotype in the } \\
\text { resulted plant population }\end{array}$} & \multirow{2}{*}{2.1} \\
\hline & 2 -nd & $Q p_{12 . t}{ }^{*}$ & $Q p_{22 . t}$ & & & \\
\hline \multirow{2}{*}{3} & 1 -st & $Q p_{21 . t}$ & $Q p_{31 . t}{ }^{*}$ & $Q p_{31 . t}=\left[\left(\mathrm{P}_{21}-\mathrm{P}_{0}\right) \cdot \psi_{1 . t}+\mathrm{P}_{0}\right] \cdot \alpha_{t}$ & $\begin{array}{l}\alpha_{t} \cdot P_{21}-\text { maximal number of seeds } \\
\text { formed by } 1 \text {-st plant genotype at } \psi_{1 . t}=1\end{array}$ & 2.2 \\
\hline & 2 -nd & $Q p_{22 . t}$ & $Q p_{32 . t}{ }^{*}$ & $Q p_{32 . t}=\left[\left(\mathrm{P}_{22}-\mathrm{P}_{0}\right) \cdot \psi_{2 . t}+\mathrm{P}_{0}\right] \cdot\left(1-\alpha_{t}\right)$ & $\begin{array}{l}\left(1-\alpha_{1}\right) \cdot P_{22}-\text { the same for } 2 \text {-nd plant } \\
\text { genotype at } \psi_{2, t}=1\end{array}$ & 2.3 \\
\hline
\end{tabular}

* Till the start of Step 2 and after the finish of Step 3 the plant population is represented by dormant seeds.

** Variables (parameters dependent on the number of cycle, $t$ ) are given in italics.

In order to implement recurrent calculations, number of seeds for 1 -st and 2 -nd plant genotypes obtained at the end of Step 3 of t-th cycle are used as the starting conditions Step 2 of $(\mathrm{t}+1)$-th cycle: $Q p_{11 . t+1}=Q p_{3 . t}, Q p_{12 . t+1}=Q p_{32 . t}$.

\section{Formation of seeds by plants.}

Impacts of mutualistic interaction on host fitness is reflected by linear dependencies of the numbers of seeds formed by 1 -st and 2 -nd plant genotypes $\left(Q p_{31 . t}, Q p_{32 . t}\right)$ on the $\psi_{1 . t}$ and $\psi_{2 . t}$ values. These dependencies correspond to Darwinian selection in plant population which is dependent on the symbiosis efficiency as it is represented by formulae from Table 2 (rearrangements 2.2, 2.3).

\section{Step 4. Decomposition of symbiosis}

At the beginning of Step 4, plants have completed the seed formation and extinct while bacteria from rhizosphere and nodules are released into soil where a temporary excess of cells is formed ("population wave" with the amplitude calculated as a ratio of total number of bacterial cells to the constant capacity of soil habitat, S). Afterwards, number of bacteria is reduced to the equilibrium level $\mathrm{S}$ due to differential extinction of two genotypes. The relevant Darwinian selection pressure is quantified by the ratio of the $\mathrm{P}: M$ extinction rates $(\mathrm{w})$. The resulted numbers of $\mathrm{P}$ and $\mathrm{M}$ bacteria are determined by logistic equation (Table 1, rearrangement 1.10).

\section{FATE OF MUTUALISTIC TRAITS IN A BACTERIAL POPULATION CO-EVOLVING WITH THE PLANTS}

The created model was used to implement the computer experiments, which enable us to trace the maintenance of mutualistic traits in bacterial populations based on the symbiosis-specific selective pressures operating in combination with the plant-bacteria positive metabolic feedbacks (which result in correlated changes of partners' reproductive potentials). Specifically, we address: (i) support of balanced polymorphism (genetic homeostasis) in the system of co-evolving bacterial and plant populations; (ii) fate of the mutant $(M)$ bacterial genotypes which acquired an ability for mutualism or changed specificity of its expression.

For implementing computer experiments, we created the package of programs (MathCad 2000) using the basic values of constant system parameters (Table 3 ). We analyzed the dynamics of genetic structure in symbiotic system characterized at $t$-th microevolutionary cycle by proportions of: (1) $M$ at the beginning of Step $1\left(\beta_{t}=Q_{I M S . t}: S\right)$; (2) 1 -st plant genotype at the end of Step $2\left(\alpha_{t}\right)$. The starting values of these parameters $\left(\alpha_{1}=0.001, \beta_{1}=0\right)$ correspond to very low polymorphism in the simulated system.

The computer experiments suggested that with increasing the cycle number $(t \rightarrow \infty)$, parameters of genetic structure $\left(\alpha_{t}, \beta_{t}\right)$ approximates the finite values $\left(\alpha_{\infty}, \beta_{\infty}\right)$ corresponding to steady state (genetic homeostasis) in symbiotic system. We analyzed the dependency of equilibrium point (determined by $\alpha_{\infty}$ and $\beta_{\infty}$ ) on parameters of linear ( $\mathrm{c} 1, \mathrm{c} 2, \mathrm{cp})$ and non-linear $(\mathrm{a} 1, \mathrm{a} 2, \lambda)$ transformations of genotype ratios in partners' populations. Parameters of the first group determine the Relative Competitive Ability (RCA) of bacterial or plant genotypes expressed in 
Basic values of the constant parameters of the model used in computer experiments

\begin{tabular}{|c|c|c|c|}
\hline \multirow[t]{2}{*}{ Constants* } & \multirow[t]{2}{*}{ Designations } & \multicolumn{2}{|c|}{ Microevolutionary regimes } \\
\hline & & Oscillatory & $\begin{array}{c}\text { Quasi- } \\
\text { monotonous }\end{array}$ \\
\hline \multicolumn{4}{|c|}{ Bacterial population (composed of mutant, $\mathrm{M}$ and parent, $\mathrm{P}$ ) } \\
\hline Coefficient of mutation pressure & q & $10^{-9}$ & $10^{-9}$ \\
\hline Total Inoculation Volume (IV) for rhizospheric sub-habitats of both plant genotypes & $\mathrm{R}_{0}$ & $10^{11}$ & $10^{11}$ \\
\hline Parameters of colonization of 1 -st and 2 -nd rhizospheric sub-habitats & $\mathrm{R}_{21}=\mathrm{R}_{22}$ & $2 \times 10^{11}$ & $2 \times 10^{11}$ \\
\hline Relative $(\mathrm{P}: \mathrm{M})$ multiplication rates in 1 -st and 2 -nd rhizospheric sub-habitats & $\mathrm{v} 1=\mathrm{v} 2$ & 0.9 & 0.9 \\
\hline Total Inoculation Volume (IV) for nodular sub-habitats of both plant genotypes & $\mathrm{N}_{0}$ & $5 \times 10^{11}$ & $5 \times 10^{11}$ \\
\hline Parameters of colonization of 1 -st and 2 -nd nodular sub-habitats & $\mathrm{N}_{21}=\mathrm{N}_{22}$ & $6 \times 10^{11}$ & $10^{12}$ \\
\hline RCA index for inoculation of 1 -st nodular sub-habitat & $\mathrm{c} 1$ & 0.2 & 0.5 \\
\hline FDS index for inoculation of 1 -st nodular sub-habitat & a1 & 0.7 & 0.6 \\
\hline RCA index for inoculation of 2 -nd nodular sub-habitat & $\mathrm{c} 2$ & 5 & 1.1 \\
\hline FDS index for inoculation of 2 -nd nodular sub-habitat & a2 & 0.7 & 0.6 \\
\hline Relative (P : M) multiplication rates in 1-st and 2-nd nodular sub-habitats & $\omega 1$ and $\omega 2$ & 0.9 and 1.1 & 0.9 and 1.1 \\
\hline Volume of soil habitat & $\mathrm{S}$ & $10^{12}$ & $10^{12}$ \\
\hline Relative $(\mathrm{P}: \mathrm{M})$ extinction rates in soil habitat & w & 1.1 & 1.1 \\
\hline \multicolumn{4}{|c|}{ Plant population (composed of 1 -st and 2 -nd genotypes) } \\
\hline Total number of plants at the end of Step 2 of $t$-th cycle & $\mathrm{P}_{0}$ & $10^{7}$ & $5 \times 10^{7}$ \\
\hline $\begin{array}{l}\text { Maximal numbers of plants of } 1 \text {-st and } 2 \text {-nd genotypes at the end of } \\
\text { Step } 3 \text { of } t \text {-th cycle (at } \psi_{1 . \mathrm{t}}=\psi_{2 . \mathrm{t}}=1 \text { ) }\end{array}$ & $\mathrm{P}_{21}$ and $\mathrm{P}_{22}$ & $\begin{array}{l}3 \times 10^{8} \text { and } \\
2 \times 10^{8}\end{array}$ & $\begin{array}{l}2 \times 10^{8} \text { and } \\
10^{8}\end{array}$ \\
\hline RCA index for competition for survival at the seed germination & cp & 2 & 1.5 \\
\hline FDS index for competition for survival at the seed germination & $\lambda$ & 0.98 & 0.6 \\
\hline
\end{tabular}

* RCA - relative competitive ability, FDS - frequency dependent selection.

the absence of FDS (we called these parameters "RCA indices"), while parameters of second group determine FDS pressures in partners" populations ("FDS indices"). The effects of variation in each of these parameters were studied under the fixed values of the other parameters (Table 3) according to parameter variation method (Strigul and Kravchenko, 2006).

We demonstrated that the steady state in symbiotic system may be reached under two microevolutionary regimes: oscillatory (typically, represented by damping oscillation) and quasi-monotonous (Fig. 2). The first regime (under which the $\beta_{t}$ function surpasses no less than four extremes) is characterized by the "constant of oscillation damping" $(\tau)$ determined using the graphical method (Fig. 2A); decrease of $\tau$ corresponds to a suppression of oscillations. The model analysis demonstrate that oscillatory regime is implemented when the negative FDS pressure in plant population is low ( $\lambda$ values are close to 1$)$ while the quasi-monotonous regime ( $\beta_{t}$ function surpasses no more than three extremes; Fig. $2 \mathrm{C}$ ) is implemented when this pressure is high ( $\lambda$ values are sufficiently less than 1 ).
Due to transition of plant population from negative FDS $(\lambda<1)$ to positive FDS $(\lambda>1)$, non-damping oscillations may be induced $(\tau=\infty)$. The FDS pressure implemented in bacteria population (determined by coefficients a $1, \mathrm{a} 2$ ) also influences $\tau$ value but to a lesser degree than FDS in plant population (determined by coefficient $\lambda$; Fig. 3 ).

The computer experiments demonstrate that under oscillatory regime, establishment of balanced polymorphism in bacterial population $\left(\beta_{\infty}>0\right)$ requires the FDS operation during inter-strain competition for nodulation of 2 -nd plant genotype $(\mathrm{a} 2<1)$ while in the absence of this selection $(a 2=1), M$ can not be anchored and the bacterial polymorphism is not established $\left(\beta_{\infty}=0\right)$. However, under quasi-monotonous regime, bacterial polymorphism may be established if FDS is implemented during competition for nodulation of only 1 -st plant genotype $(\mathrm{a} 1<1$; $\mathrm{a} 2=1)$ or of only 2 -nd plant genotype $(\mathrm{a} 1=1 ; \mathrm{a} 2<1)$. Under both regimes, full absence of FDS in bacterial population $(\mathrm{a} 1=\mathrm{a} 2=1)$ results in the absence of its polymorphism since the mutations changing the symbiotic properties are not anchored $\left(\beta_{\infty}=0\right)$. 
A

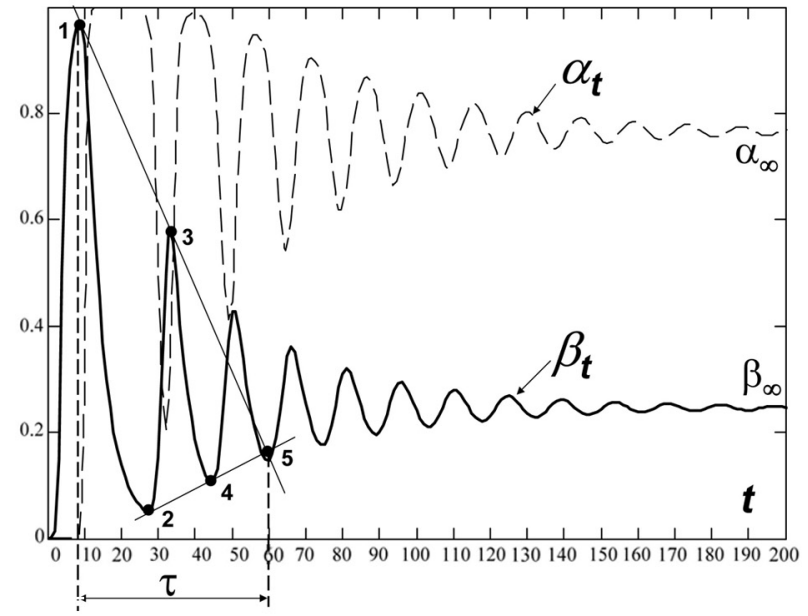

$\mathrm{B}$

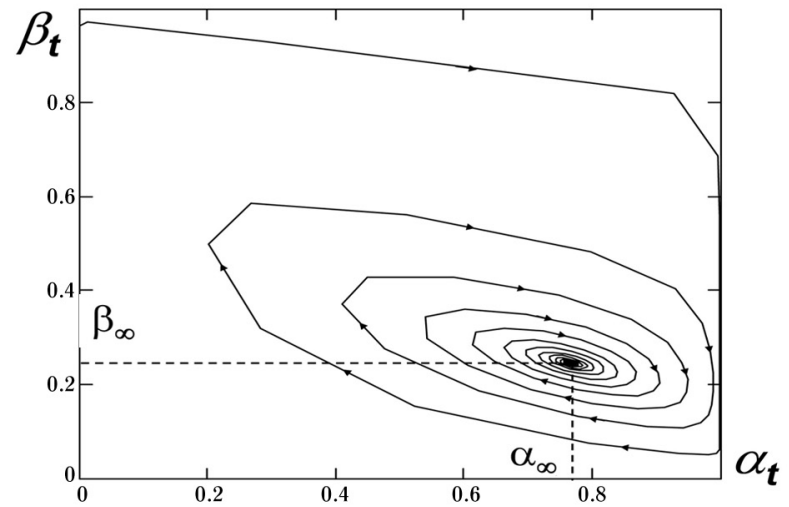

C

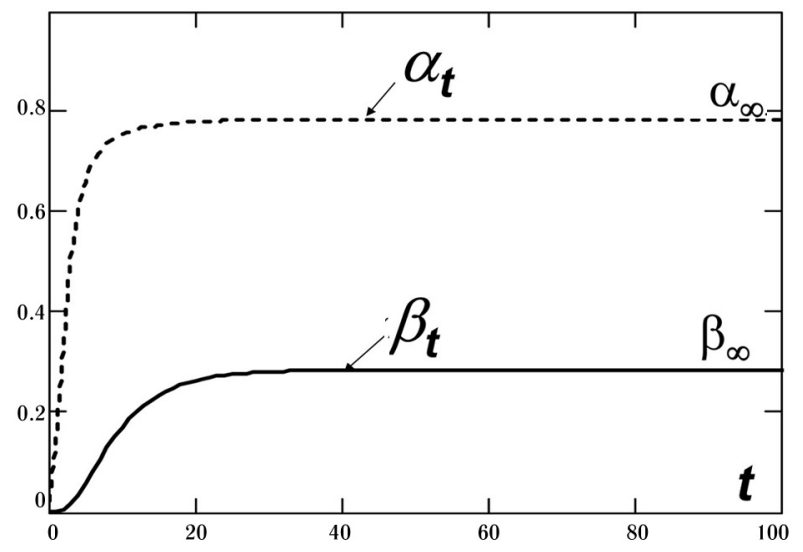

Fig. 2. Dynamics of plant and bacterial populations leading to genetic homeostasis in symbiotic system.

A - proportions of 1 -st genotype in plant population $\left(\alpha_{t}\right)$ and of mutant in rhizobia population $\left(\beta_{\mathrm{t}}\right)$ as dependent on the number of cycle $(t)$ under the oscillatory regime of microevolution ( $\beta_{\mathrm{t}}$ function surpass no less than four extremes). Points used to determine the "constant of oscillation damping" $(\tau)$ are: 1 and $3-$ first two maximums of $\beta$ oscillations, 2 and $4-$ first two minimums of $\beta_{+}$oscillations; 5 crossing of lines $1-3$ and $2-4$. The $\tau$ value is determined as the difference between numbers of cycles corresponding to points 5 and 1 . $\mathrm{B}$ - phase portrait of trajectory in damping oscillatory process presented in Fig. 2A (the equilibrium point is determined by $\alpha_{\infty}$ and $\beta_{\infty}$ values).

$\mathrm{C}-$ changes of $\alpha_{t}$ and $\beta_{\mathrm{t}}$ values under the quasi-monotonous regime ( $\beta_{\mathrm{t}}$ function surpass no more than three extremes).
An important goal for analyzing the model was to reveal the conditions under which the $M$ having novel $\mathrm{N}_{2}$ fixing capacities dominate in population $\left(\beta_{\infty}>0.5\right)$. We demonstrated that this domination occurs for both mutation types under quasi-monotonous regime, and for 2 -nd $M$ type under oscillatory regime (Tables 4, 5). For 1 -st mutation type ("genuine mutualist"), domination under oscillatory regime is restricted to the maximal tested values of RCA indices in plant population $(\mathrm{cp} \geq 3)$ or of RCA index in bacterial population competing for nodulation of 1 -st plant genotype $(\mathrm{c} 1 \geq 0.3)$ (Table 4$)$. These data suggest that genetic stability of system (represented by quasi-monotonous regime) is favorable for evolution of mutualistic interactions. Moreover, under the oscillatory regime of microevolution, establishment of mutualism leads to a genetic stabilization of symbiotic system: for 1 -st type of bacterial mutations, $\tau$ values are lower (oscillations are suppressed) with respect to 2 -nd type of mutations (Fig. 3).

Surprisingly, we revealed a decrease of bacterial polymorphism (represented by an increase of difference between $\beta_{\infty}$ and 0.5 value typical for a maximally diverse dimorphic population) resulted from an enhancement of negative FDS in bacteria (indicated by the decreases of FDS indices a1 and a2) (Table 5). In the previously suggested models (Provorov and Vorobyov, 2000, 2006) which did not account for the plant polymorphism (and therefore did not address the partners' co-evolution) enhancement of FDS in bacterial population uniformly resulted in an increase of its polymorphism (as it normally occurs in free-living organisms). It is important to note that enhancement of negative FDS in plant population (decrease of $\lambda$ ) always results in the increase of bacterial polymorphism (approximation of $\beta_{\infty}$ to 0.5 ; Table 5) suggesting that FDS implemented in plants is more important for supporting the bacterial polymorphism than "own bacterial" FDS.

The suggested model allows us to look for the reverse impacts of selection pressures implemented in bacteria on the dynamics of plant population. These impacts are pronounced since at the absence of $\operatorname{FDS}(\lambda=1)$ or even at the positive FDS $(\lambda=1.05)$ in plant population it maintains a polymorphism $\left(\alpha_{\infty}>0\right)$ supported by FDS implemented in bacterial population (Table 6 ). The domination of 1 -st plant genotype $\left(\alpha_{\infty}>0.5\right)$ which is initially rare $\left(\alpha_{1}=0.001\right)$ is restricted to oscillatory regime implemented with 1 -st type of bacterial mutations (Tables 6, 7).

It is important to note that Darwinian selection implemented in bacterial population have the negligible impacts on the symbiosis microevolution. Only a slight dependency of the homeostasis point $\left(\alpha_{\infty}, \beta_{\infty}\right)$ was found for the Darwinian selection pressure implemented during the differential $\mathrm{P}$ and $\mathrm{M}$ extinction in the soil habitat (w), while no influence of Darwinian selection pressures implemented during 

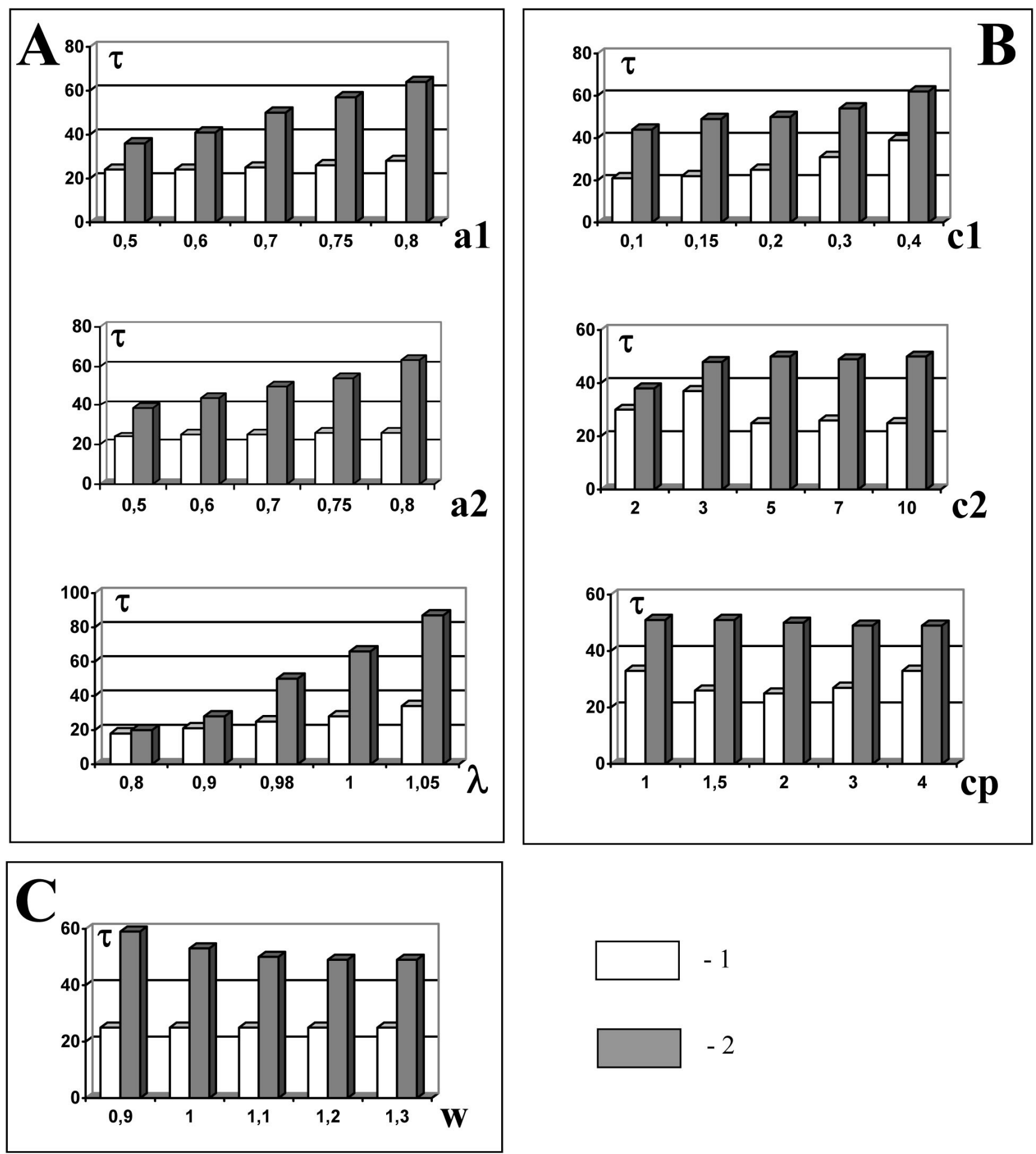

Fig. 3. Dependency of the constant of oscillation damping $(\tau)$ on parameters of selective pressures elicited by 1 -st and 2 -nd types of bacterial mutations

A - on frequency-dependent selection (FDS indices) in bacterial population (a 1, a2) and in plant population $(\lambda)$;

$\mathrm{B}$ - on relative competitive ability (RCA indices) in bacterial population ( $1 \mathrm{c} 2$ ) and in plant population (cp);

$\mathrm{C}$ - on constant w reflecting the Darwinian selection pressure in the soil population. 
Table 4

Impacts on the finite $\boldsymbol{\beta}_{\infty}$ value of relative competitive ability (RCA) indices in bacterial population when competing for 1-st (c1) and 2-nd (c2) plant genotypes as well as RCA indices in plant population (cp)

\begin{tabular}{|c|c|c|c|c|c|}
\hline \multicolumn{3}{|c|}{ Oscillatory regime } & \multicolumn{3}{|c|}{ Quasi-monotonous regime } \\
\hline $\mathrm{c} 1$ & 1-st type of mutations & 2-nd type of mutations & $\mathrm{cl}$ & 1-st type of mutations & 2 -nd type of mutations \\
\hline 0.1 & 0.129 & 0.617 & 0.3 & 0.737 & 0.677 \\
\hline 0.15 & 0.234 & 0.704 & 0.4 & 0.761 & 0.715 \\
\hline 0.2 & 0.344 & 0.768 & 0.5 & 0.784 & 0.752 \\
\hline 0.3 & 0.554 & 0.863 & 0.6 & 0.806 & 0.786 \\
\hline 0.4 & 0.732 & 0.936 & 0.7 & 0.824 & 0.817 \\
\hline \multicolumn{3}{|l|}{$\mathrm{c} 2$} & \multicolumn{3}{|l|}{$\mathrm{c} 2$} \\
\hline 2 & 0.258 & 0.492 & 0.9 & 0.790 & 0.732 \\
\hline 3 & 0.306 & 0.642 & 1.0 & 0.787 & 0.743 \\
\hline 5 & 0.344 & 0.768 & 1.1 & 0.784 & 0.752 \\
\hline 7 & 0.360 & 0.826 & 1.2 & 0.782 & 0.759 \\
\hline 10 & 0.372 & 0.873 & 1.3 & 0.780 & 0.766 \\
\hline \multicolumn{3}{|l|}{ cp } & \multicolumn{3}{|l|}{$\mathrm{cp}$} \\
\hline 1 & 0.075 & 0.602 & 1 & 0.579 & 0.553 \\
\hline 1.5 & 0.206 & 0.705 & 1.3 & 0.720 & 0.688 \\
\hline 2 & 0.344 & 0.768 & 1.5 & 0.784 & 0.752 \\
\hline 3 & 0.586 & 0.843 & 2 & 0.880 & 0.853 \\
\hline 4 & 0.763 & 0.885 & 3 & 0.952 & 0.937 \\
\hline
\end{tabular}

Table 5

Impacts on the finite $\boldsymbol{\beta}_{\infty}$ value of frequency-dependent selection (FDS) indices in bacterial population when competing for for 1 -st (a1) and 2 -nd (a2) plant genotypes as well as FDS indices in plant population $(\lambda)$

\begin{tabular}{|c|c|c|c|c|c|}
\hline \multicolumn{3}{|c|}{ Oscillatory regime } & \multicolumn{3}{|c|}{ Quasi-monotonous regime } \\
\hline al & 1-st type of mutations & 2-nd type of mutations & al & 1-st type of mutations & 2-nd type of mutations \\
\hline 0.5 & 0.245 & 0.829 & 0.4 & 0.800 & 0.776 \\
\hline 0.6 & 0.300 & 0.796 & 0.5 & 0.793 & 0.765 \\
\hline 0.7 & 0.344 & 0.768 & 0.6 & 0.784 & 0.752 \\
\hline 0.75 & 0.362 & 0.756 & 0.7 & 0.773 & 0.736 \\
\hline 0.8 & 0.379 & 0.744 & 0.8 & 0.758 & 0.718 \\
\hline \multicolumn{3}{|c|}{$\mathrm{a} 2$} & \multicolumn{3}{|c|}{$\mathrm{a} 2$} \\
\hline 0.5 & 0.334 & 0.814 & 0.4 & 0.780 & 0.765 \\
\hline 0.6 & 0.339 & 0.791 & 0.5 & 0.782 & 0.759 \\
\hline 0.7 & 0.344 & 0.768 & 0.6 & 0.784 & 0.752 \\
\hline 0.75 & 0.346 & 0.757 & 0.7 & 0.787 & 0.743 \\
\hline 0.8 & 0.349 & 0.747 & 0.8 & 0.790 & 0.733 \\
\hline \multicolumn{3}{|c|}{$\lambda$} & \multicolumn{3}{|c|}{$\lambda$} \\
\hline 0.8 & 0.456 & 0.749 & 0.5 & 0.732 & 0.709 \\
\hline 0.9 & 0.399 & 0.760 & 0.55 & 0.756 & 0.729 \\
\hline 0.98 & 0.344 & 0.768 & 0.6 & 0.784 & 0.752 \\
\hline 1.0 & 0.329 & 0.771 & 0.65 & 0.817 & 0.778 \\
\hline 1.05 & 0.289 & 0.772 & 0.7 & 0.853 & 0.808 \\
\hline
\end{tabular}


Table 6

Impacts on the finite $\alpha_{\infty}$ value of frequency-dependent selection (FDS) indices in bacterial population when competing for 1-st (a1) and 2-nd (a2) plant genotypes as well as FDS indices in plant population ( $\lambda$ )

\begin{tabular}{|c|c|c|c|c|c|}
\hline \multicolumn{3}{|c|}{ Oscillatory regime } & \multicolumn{3}{|c|}{ Quasi-monotonous regime } \\
\hline al & 1-st type of mutations & 2 -nd type of mutations & al & 1-st type of mutations & 2-nd type of mutations \\
\hline 0.5 & 0.780 & 0.213 & 0.4 & 0.333 & 0.342 \\
\hline 0.6 & 0.739 & 0.230 & 0.5 & 0.311 & 0.325 \\
\hline 0.7 & 0.706 & 0.246 & 0.6 & 0.284 & 0.305 \\
\hline 0.75 & 0.693 & 0.253 & 0.7 & 0.243 & 0.285 \\
\hline 0.8 & 0.681 & 0.260 & 0.8 & 0.219 & 0.264 \\
\hline \multicolumn{3}{|l|}{$\mathrm{a} 2$} & \multicolumn{3}{|l|}{$\mathrm{a} 2$} \\
\hline 0.5 & 0.697 & 0.216 & 0.4 & 0.312 & 0.323 \\
\hline 0.6 & 0.702 & 0.232 & 0.5 & 0.299 & 0.315 \\
\hline 0.7 & 0.706 & 0.246 & 0.6 & 0.284 & 0.305 \\
\hline 0.75 & 0.709 & 0.253 & 0.7 & 0.268 & 0.293 \\
\hline 0.8 & 0.711 & 0.216 & 0.8 & 0.250 & 0.278 \\
\hline \multicolumn{3}{|l|}{$\lambda$} & \multicolumn{3}{|l|}{$\lambda$} \\
\hline 0.8 & 0.597 & 0.266 & 0.5 & 0.301 & 0.319 \\
\hline 0.9 & 0.653 & 0.255 & 0.55 & 0.293 & 0.313 \\
\hline 0.98 & 0.706 & 0.246 & 0.6 & 0.284 & 0.305 \\
\hline 1.0 & 0.721 & 0.244 & 0.65 & 0.274 & 0.297 \\
\hline 1.05 & 0.759 & 0.242 & 0.7 & 0.262 & 0.286 \\
\hline
\end{tabular}

Table 7

Impacts on the finite $\alpha_{\infty}$ value of relative competitive ability (RCA) indices in bacterial population when competing for 1-st (c1) and 2-nd (c2) plant genotypes as well as RCA indices in plant population (cp)

\begin{tabular}{|c|c|c|c|c|c|}
\hline \multicolumn{3}{|c|}{ Oscillatory regime } & \multicolumn{3}{|c|}{ Quasi-monotonous regime } \\
\hline $\mathrm{c} 1$ & 1-st type of mutations & 2-nd type of mutations & $\mathrm{cl}$ & 1-st type of mutations & 2-nd type of mutations \\
\hline 0.1 & 0.872 & 0.346 & 0.3 & 0.176 & 0.228 \\
\hline 0.15 & 0.789 & 0.286 & 0.4 & 0.226 & 0.261 \\
\hline 0.2 & 0.706 & 0.246 & 0.5 & 0.284 & 0.305 \\
\hline 0.3 & 0.555 & 0.196 & 0.6 & 0.305 & 0.360 \\
\hline 0.4 & 0.432 & 0.165 & 0.7 & 0.421 & 0.423 \\
\hline \multicolumn{3}{|l|}{$\mathrm{c} 2$} & \multicolumn{3}{|l|}{$\mathrm{c} 2$} \\
\hline 2 & 0.606 & 0.365 & 0.9 & 0.253 & 0.276 \\
\hline 3 & 0.668 & 0.311 & 1.0 & 0.269 & 0.292 \\
\hline 5 & 0.706 & 0.246 & 1.1 & 0.284 & 0.305 \\
\hline 7 & 0.721 & 0.207 & 1.2 & 0.299 & 0.316 \\
\hline 10 & 0.731 & 0.169 & 1.3 & 0.314 & 0.325 \\
\hline \multicolumn{3}{|l|}{$\mathrm{cp}$} & \multicolumn{3}{|l|}{$\mathrm{cp}$} \\
\hline 1 & 0.948 & 0.412 & 1 & 0.350 & 0.367 \\
\hline 1.5 & 0.835 & 0.311 & 1.3 & 0.305 & 0.326 \\
\hline 2 & 0.706 & 0.246 & 1.5 & 0.284 & 0.305 \\
\hline 3 & 0.463 & 0.168 & 2 & 0.253 & 0.271 \\
\hline 4 & 0.269 & 0.122 & 3 & 0.229 & 0.239 \\
\hline
\end{tabular}


the differential $\mathrm{P}$ and $\mathrm{M}$ multiplication in rhizospheral (v1, v2) and nodular $(\omega 1, \omega 2)$ habitats was revealed (data not shown). No effect of $\mathrm{v} 1, \mathrm{v} 2, \omega 1, \omega 2$ on constant of oscillation damping $(\tau)$ was revealed and only w variation exhibit a slight influence on $\tau$ (Fig. 3C). These data suggests that in bacterial populations, Darwinian selection (in contrast to FDS ) has no significant role in evolution of mutualistic traits. However, in plant population both Darwinian selection and FDS are highly important for supporting the symbiotic mutualism.

\section{DISCUSSION}

The facultative mutualism represents an evolutionary enigmatic phenomenon since in many symbiotic systems, partners maintain the genes (express the traits) which benefit the co-habitants even at the expense of survival in the owners of these genes/traits. It was argued repeatedly (Frank, 1996; Douglas, 1998; Simms and Taylor, 2002; Gundel et al., 2007) that mutualistic traits should be stable in the microbes which are involved in the obligatory symbioses and are vertically transmitted in host generations ("forced altruism" based on the full dependency of both partners on mutualistic interactions; Darlington, 1978). For facultative symbioses, mechanisms for mutualism evolution are poorly understood because a mixing of lineages in free-living microsymbiont populations can reduce the host benefit due to distribution of "symbiotic cheaters" which should be adaptively advantageous with respect to "genuine mutualists" (Frank, 1996; Douglas, 1998).

Within the "reciprocal altruism" hypothesis, evolution of facultative mutualism may be ascribed to group selection, which favors the microbial genotypes expressing the host-beneficial traits due a return of costs for this expression (Frank, 1994). With respect to rhizobia-legume symbiosis, this hypothesis assumes that allocation of plant-derived C-compounds implemented in favor of $\mathrm{N}_{2}$-fixing strains leads to inter-deme or kin selection in rhizobia population (Provorov et al., 2008) enhanced by host "sanctions" against non-fixing strains (Denison, 2000). This mechanism may be effective only if the in planta multiplication of rhizobia is essentially clonal (i. e., $\mathrm{N}_{2}$-fixing nodules do not contain the strains which are not capable of $\mathrm{N}_{2}$ fixation). However, the empirical data demonstrate that field rhizobial populations are crowded by the ineffective but virulent (cheating) strains responsible for the broad distribution of mixed $\left(\mathrm{Fix}^{+}+\right.$ Fix $^{-}$) nodular infections (Bassam et al., 1987; Denison, 2000). Under these conditions, "symbiotic cheaters" which mimic the "genuine mutualists" are expected to dominate in the system and can even block the mutualism evolution since they extract nutritional resources from host but do not spend their own resources for expressing the host-beneficial traits.
However, a stable co-existence of "symbiotic cheaters" and "genuine mutualists" was revealed in $\mathrm{N}_{2}$-fixing symbioses formed by dicots with rhizobia or Frankia as well as in photosynthetic symbioses between invertebrates and phototrophic microbes (Douglas, 1998). Moreover, legume-rhizobia symbioses had undergo a prolonged evolution towards an improved mutualism efficiency as it is evident from increasing complexity of nodular structure (Sprent, 2007) and from the progressive specialization of the rhizobial nitrogenase system for symbiotic purposes (Provorov et al., 2008). Such evolution is not correlated to transformation of the facultative mutualistic symbioses into obligatory ones which may be blocked by a high cost of vertical transmission (Genkai-Kato and Yamamura, 1999) or by an excessive ecological specialization of host restricting its adaptive amplitude (Douglas, 1998).

In this paper we present the mathematical model which describes the evolution of mutualism in facultative rhizobia-legume symbiosis under the impacts of positive partners' feedbacks based on the metabolic ( $\mathrm{C}-\mathrm{N})$ exchange. We demonstrate that frequency dependent selection (FDS) operating in the co-evolving populations in combination with Darwinian selection and positive partners' feedbacks may ensure anchoring or even domination of "genuine mutualists" in spite of continuous competition with "symbiotic cheaters". Specifically, we suggest that FDS in bacterial population ensures an equilibrium between "genuine mutualists" and "symbiotic cheaters" that may be shifted in favor of the first symbiont type due to Darwinian selection implemented within plant population under impact of improved symbiotic efficiency. The revealed correlation between establishment of mutualism and genetic stability in rhizobia-legume system may be valid for different symbioses (Law and Levis, 1983; Pellmur and Huth, 1994).

In a more general context, the created model allows us to represent the facultative symbiosis as an integrated system wherein the bacterial genotypes which express the host-beneficial (mutualistic) traits may be supported under genetic homeostasis caused by differently directed selective pressures operating in partners' populations. These pressures are resulted from positive metabolic feedbacks (coordinated increases of the partners' reproductive activities due to symbiotic interaction) representing an evolutionary mechanism which ensures domination of "genuine mutualists" over the "symbiotic cheaters". This is why evolution of facultative mutualism towards an increased efficiency is possible without transformation of symbioses into obligatory forms (including vertical transmission of microsymbionts in host generations) and without a specific allocation of host-provided rewards and sanctions among "genuine mutualists" and "symbiotic cheaters" (resulted from the clonal in planta propagation of microbes). Given the broad distribution of FDS pressures and of positive feedbacks in the symbiotic interactions, one can suggest that the similar mechanisms can operate in many other mutualistic systems. 


\section{ACKNOWLEDGEMENT}

Research is supported by RFBR grant 06-04-48800a.

\section{Literature}

1. Amarger N., Lobreau J.P., 1982. Quantitative study of nodulation competitiveness in Rhizobium strains // Appl. Environ. Microbiol. Vol. 44. P. 583-588.

2. Bassam B.J., Mahanty H. K., Gresshoff P. M., 1987. Symbiotic interaction of auxotrophic mutants of $R h i$ zobium trifolii with white clover (Trifolium repens) // Endocyt. C. Res. Vol. 4. P. 331-347.

3. Bethlenfalvay G. I., Abu-Shakra S. S., Phillips D. A., 1978. Interdependence of nitrogen nutrition and photosynthesis in Pisum sativum L. II Host plant response to nitrogen fixation by Rhizobium strains // Plant Physiol. Vol. 62. P. $131-133$.

4. Brewin N. J., 2004. Plant cell wall remodeling in the Rhizobium-legume symbiosis // Crit. Rev. Plant. Sci. Vol. 23. P. 1-24.

5. Darlington P. J., 1978. Altruism: its characteristics and evolution // Proc. Natl. Acad. Sci. USA. Vol. 75. P. 385-389.

6. Denison R. F., 2000. Legume sanctions and the evolution of symbiotic cooperation by rhizobia // The Amer. Naturalist. Vol. 156. P. 567-576.

7. Denison R. F., Kiers E. T., 2004. Lifestyle alternatives for rhizobia: mutualism, parasitism and forgoing symbiosis // FEMS Microbiol. Lett. Vol. 237. P. 187-193.

8. Douglas A.E., 1994. Symbiotic Interactions. - Oxford, New York, Toronto: Oxford Univ. Press, 148 p.

9. Douglas A. E., 1998. Host benefit and the evolution of specialization in symbiosis // Heredity. Vol. 81. P. 599-603.

10. Frank S. A., 1994. Genetics of mutualism: the evolution of altruism between species // J. Theor. Biol. Vol. 170. P. 393-400.

11. Frank S. A., 1996. Host-symbiont conflict over the mixing of symbiotic lineages // Proc. Roy. Soc. London. B. Vol. 263. P. 339-344.

12. Genkai-Kato M., Yamamura N., 1999. Evolution of mutualistic symbiosis without vertical transmission // Theor. Populat. Biol. Vol. 55. P. 309-323.

13. Gundel P. E., Batista W. B., Texeira M. et al., 2008. Neotyphodium endophyte infection frequency in annual grass populations: relative importance of mutualism and transmission efficiency // Proc. Roy. Soc. B. Vol. 275. P. 897-905.

14. Kiers E. T., Rousseau R. A., West S. A., Denison R. F., 2003. Host sanctions and the legume-Rhizobium mutualism // Nature. Vol. 425. P. 78-81.

15. Kubitschek H. E., 1974. Operation of selection pressure on microbial populations // Evolution in the Microbial World. Cambridge: Univ. Press. P. 105-130.
16. Law R., Lewis D. H., 1983. Biotic environments and the maintenance of sex - some evidence from mutualistic symbioses // Biol. J. Linn. Soc. Vol. 20 P. 249-276.

17. Pellmur O., Huth C. J., 1994. Evolutionary stability of mutualism between yuccas and yucca moths // Nature. Vol. 372. P. 257-260.

18. Person C., Samborski D. J., Rohringer R., 1962. The gene-for-gene concept // Nature. Vol. 194. P. 561-562.

19. Pimentel D., 1968. Population regulation and genetic feedback // Science. Vol. 159. P. 1432-1437.

20. Provorov N. A., Vorobyov N. I., 2000. Population genetics of rhizobia: construction and analysis of an "infection and release" model // J. Theor. Biol. Vol. 205. P. 105-119.

21. Provorov N. A., Vorobyov N. I., 2006. Interplay of Darwinian and frequency-dependent selection in the hostassociated microbial populations // Theor. Populat. Biol. Vol. 70. P. 262-272.

22. Provorov N. A., Vorobyov N. I., Andronov E. E., 2008. Macro- and micro-evolution of bacteria in symbiotic systems // Russian Journal of Genetics. Vol. 44. P. 6-20.

23. Sessitsch A., Howieson J. G., Perret X. et al., 2002. Advances in Rhizobium research // Crit. Rev. Plant Sci. Vol. 21. P. 323-378.

24. Simms E. L., Taylor D. L., 2002. Partner choice in nitrogen-fixing mutualisms of legumes and rhizobia // Integrative and Comparative Biology. Vol. 42. P. 369-380.

25. Smith S. E., Read D. J., 1997. Mycorrhizal Symbiosis (second edition). - San Diego, London, New York, Boston, Sydney, Tokyo, Toronto: Academic Press, 580 p.

26. Sprent J. I., 2007. Evolving ideas of legume evolution and diversity: a taxonomic perspective on the ocurrence of nodulation // New Phytologist. Vol. 174. P. 11-25.

27. Strigul N. S., Kravchenko L. V., 2006. Mathematical modeling of PGPR inoculation into the rhizosphere // Environmental Modeling and Software. Vol. 21. P. 1158-1171.

28. Streeter J., 1995. Integration of plant and bacterial metabolism in nitrogen fixing systems // Nitrogen Fixations: Fundamentals and Applications / Eds. I. A. Tikhonovich et al. Dordrecht, Boston, London: Kluwer Acad. Publ. P. 67-76.

29. Tikhonovich I. A., Provorov N. A., 2007. Cooperation of plants and microorganisms: getting closer to the genetic construction of sustainable agro-systems // Biotechnology Journal. Vol. 2. P. 833-848.

30. Timmers A. C. S., Soupene E., Auriac M. C. et al., 2000. Saprophytic intracellular rhizobia in alfalfa nodules // Mol. Plant-Microbe Interact. Vol. 13. P. $1204-1213$.

31. Timofeeff-Ressousky N. W., Jablokov A. V., Glotov N. V., 1977. Grundriss der Populationslehre. Jena: Gustav Fisher Verlag, 335 p. 
32. Vance C. P., Heichel G. H., 1991. Carbon dioxide assimilation in pulvini of Phaseolus vulgaris L. // Annu. Rev. Plant Physiol. Plant Molec. Biol. Vol. 42. P. 37-42.

33. Williams G. S., 1966. Adaptation and Natural Selection. - Princeton, New York: Princeton Univ. Press, $416 \mathrm{p}$.

Моделирование коэволюции бактерий и растений при образовании мутуалистического симбиоза

Проворов Н. А., Воробьев Н. И.

PЕЗЮМЕ: Создана модель эволюции способности к мутуалистическому симбиозу у клубеньковых бактерий, которая основана на их положительной обратной связи с бобовыми растениями (она описана параметрами, определяющими возрастание репродуктивного потенциала обоих партнеров в зависимости от эффективности симбиоза). Компьютерные эксперименты показали, что частотно-зависимый отбор, происходящий в популяциях ризобий при конкуренции за образование клубеньков, способствует закреплению у бактерий мутаций, которые либо приводят к возникновению признаков мутуализма, либо изменяют специфичность их проявления. Закрепление признаков мутуализма происходит более успешно в монотонном, нежели в колебательном режиме эволюции и способствует повышению генетической стабильности симбиосистемы.

Ж КЛЮЧЕВЫЕ СЛОВА: клубеньковые бактерии, бобовые растения, математическое моделирование, частотно-зависимый отбор, микроэволюция, мутуалистический симбиоз, компьютерные эксперименты 